\title{
Influence of Provider Characteristics and Insurance Status on Maternal Serum Alpha-Fetoprotein Screening
}

\author{
Laura D. Jenkins-Woelk, MD, MPH, Laura-Mae Baldwin, MD, MPH, Tina R. Raine, MD, \\ MPH, L. Gary Hart, PbD, Mereditb A. Fordyce, PbC, and Roger A. Rosenblatt, MD, MPH
}

Background: The maternal serum alpha-fetoprotein test (MSAFP) was developed to screen for neural tube defects. Little is known about the adoption of the MSAFP test. This study examines the effect of provider specialty and geographic location and patient insurance status on MSAFP test use in Washington State.

Methods: We conducted a retrospective cohort study of MSAFP use in low-risk obstetric patients of five provider groups. MSAFP use was examined for Medicaid and privately insured patients, as well as for the patients of the five provider types.

Results: Patients of urban and rural obstetrician-gynecologists were most likely to have MSAFP testing (80.4 percent and 77.0 percent, respectively); patients of urban certified nurse midwives and rural family physicians were least likely to have MSAFP testing (64.2 percent and 62.2 percent, respectively). Patients of certified nurse midwives were more likely to decline MSAFP testing when offered ( 26.1 percent). Medicaidinsured women were significantly less likely to have MSAFP testing than privately insured women (60.5 percent versus 79.1 percent, $P \leq 0.05$ ).

Conclusions: Providers and patients did not uniformly use MSAFP screening. Efforts should be made to ensure that all patients are adequately informed of screening tests for neural tube defects. (J Am Board Fam Pract 1998;11:357-65.)

The birth of an infant with a neural tube defect can be an emotionally devastating event for a family. Neural tube defects, which include anencephaly, spina bifida, and encephalocele, occur in 1 to $2 / 1000$ live births in the United States and can result in serious long-term disability and infant mortality. ${ }^{1-3}$ In most cases the cause is unknown and thought to be multifactorial. ${ }^{4}$ Couples in which one partner has a neural tube defect or

Submitted, revised, 29 January 1998.

From the Duke University Department of Family and Community Medicine/University of Zimbabwe Department of Community Medicine, Chapel Hill and Harare (LDJ); the Department of Family Medicine, University of Washington, Seattle (LMB, GH, MAF, RAR); and the Department of Obstetrics and Gynecology, University of California, San Francisco (TRR). Address reprint requests to Laura-Mae Baldwin, MD, MPH, University of Washington, Department of Family Medicine, Box 354696, Seattle, WA 98195-4696.

The opinions and conclusions are those of the authors and do not necessarily represent the views of the supporting agencies and foundation.

This research was principally funded by the Agency for Health Care Policy and Research (grant \#ROI HSO6166). This research was performed while Drs. Jenkins and Raine were in the Robert Wood Johnson Foundation's Clinical Scholars Program. Additional support for this research effort was provided by the Federal Office of Rural Health Policy, Health Resources and Services Administration, Public Health Service (grant \#CSR 000007-04-0). those who have given birth to infants with neural tube defects are at increased risk for offspring with neural tube defects. Nevertheless, a family history is absent in 90 to 95 percent of couples in which neural tube defects occur. Effective prenatal recognition of most neural tube defects therefore requires screening in couples who are not considered to be high risk. ${ }^{5}$

The maternal serum alpha-fetoprotein (MSAFP) screening test for neural tube defects was developed and tested in the 1970s in Great Britain. ${ }^{6}$ Testing in the United States followed shortly thereafter. Reports indicated the test to be effective in the prenatal detection of neural tube defects, and cost analyses projected great cost savings. ${ }^{7-11}$ While the Food and Drug Administration approved alpha-fetoprotein testing in 1983, several experts expressed concerns about universal alphafetoprotein screening because of the high level of diagnostic interpretation and coordination required for such a program to function effectively. ${ }^{12-14}$ Despite the lack of consensus about universal alpha-fetoprotein testing, the American College of Obstetricians and Gynecologists (ACOG) recommended it as a screening test in its third edition of Guidelines for Perinatal Care. ${ }^{15}$ Since that time, the 
triple screen for MSAFP, human chorionic gonadotropin, and unconjugated estriol has been developed as a method for simultaneously screening for neural tube defects and detecting Down syndrome risk. ${ }^{16-18}$ Yet little is known about the degree to which even the original MSAFP test had been adopted by patients and prenatal care providers.

To date only one survey of family physicians has inquired about their MSAFP test-ordering behavior and their patients' acceptance of the test. ${ }^{19}$ No study of actual utilization of MSAFP testing has been done. We examined the use of MSAFP in a population of low-risk women in urban and rural Washington State to determine whether factors that have been associated with variation in procedure use-provider specialty and patient insurance status-affected the use of this test.

\section{Methods}

The data for this study were retrospectively abstracted from the prenatal records of randomly selected low-risk obstetric patients initiating care between 1 September 1988, and 30 August 1989, with stratified random samples of Washington State obstetric providers-urban obstetrician-gynecologists, rural obstetrician-gynecologists, urban family physicians, rural family physicians, and urban certified nurse midwives. A complete description of the study methods, including the randomization process, is found elsewhere. ${ }^{20}$

Two thousand thirty-six obstetric providers from professional society and licensing lists were stratified into the five groups based on specialty and practice location. Urban providers were defined as those practicing in counties designated as metropolitan areas. Because there were few rural certified nurse midwives, they were excluded from the study. A random sample of providers from each of the five groups was contacted to determine whether they met the eligibility criteria (performed at least 10 deliveries in 1988). If eligible, they were asked to participate in the study.

Ninety-one percent of eligible providers contacted for the study were successfully enrolled: 54 urban obstetrician-gynecologists ( 77 percent participation), 29 rural obstetrician-gynecologists (88 percent participation), 59 urban family physicians (92 percent participation), 67 rural family physicians ( 99 percent participation), and 43 urban certified nurse midwives (100 percent participation). The percentages of populations of Washington State obstetric providers represented by these providers are estimated to be 24 percent, 88 percent, 17 percent, 65 percent, and 100 percent, respectively. Information about the practices and demographics of providers was obtained by questionnaire.

Staff at each provider's office compiled the names of all patients initially booking for obstetric care with that provider during the study year. Trained chart abstractors used a one-page screening instrument to obtain basic demographic information, insurance status, ethnicity, and obstetric and medical risk factors for these patients. This information was used to select a subset of women at low obstetric risk. Low risk was defined as (1) entry into prenatal care in the first trimester (before 15 weeks' gestation), (2) maternal age between 18 and 34 years, (3) parity of less than four, (4) no history of alcohol or drug abuse, (5) having some form of insurance, either public or private, (6) no history of medical conditions (eg, hypertension), and (7) no history of obstetric complications (eg, stillbirths, more than four spontaneous abortions before 14 weeks' gestation, births before 36 weeks' gestation, gestational diabetes, preterm labor). Abstractors used a random numbers table to select up to 11 low-risk women from each provider's practice. For the providers who had fewer than 11 qualifying patients, all patients were included in the study.

Detailed prenatal care information was abstracted from the medical record of each of these low-risk women. Abstractors were instructed to record whether the MSAFP test was offered and declined, whether it was performed, or whether testing or results were not documented. The exact laboratory result, reported as the multiple of the median (MOM), was recorded when available. If the result was reported as normal or abnormal, but an exact MOM was unavailable, this finding too was recorded.

Because the data were originally collected for a study with the provider as the unit of analysis, we created compensatory weights that allowed us to examine the data with the patient as the unit of analysis. This weighting methodology allowed us to produce accurate statewide population estimates. The weights correct for the following two biases: (1) differences in provider specialty-location strata sampling rates and differences in participation rates (eg, urban family physicians were 
Table 1. Characteristics of the Patients by Provider Group (weighted estimates).

\begin{tabular}{|c|c|c|c|c|c|c|}
\hline Characteristic & $\begin{array}{l}\text { Urban } \\
\text { Ob-Gyn }\end{array}$ & $\begin{array}{c}\text { Rural } \\
\text { Ob-Gyn }\end{array}$ & Urban FP & Rural FP & $\begin{array}{l}\text { Urban } \\
\text { CNM }\end{array}$ & $\begin{array}{c}\text { Combined } \\
\text { Weighted } \\
\text { Estimates (CI) }\end{array}$ \\
\hline Age, mean $y^{*}$ & 26.6 & 25.6 & 26.0 & 25.5 & 26.6 & $\begin{array}{c}26.4 \\
(26.0-26.8)\end{array}$ \\
\hline $\begin{array}{l}\text { Race or ethnicity, \% } \\
\text { White non-Hispanic }\end{array}$ & 89.7 & 91.0 & 91.4 & 90.1 & 86.7 & $\begin{array}{c}90.0 \\
(88.0-92.0)\end{array}$ \\
\hline Others & 10.3 & 9.0 & 8.6 & 10.0 & 13.4 & $\begin{array}{c}10.0 \\
(8.0-12.0)\end{array}$ \\
\hline \multicolumn{7}{|l|}{ Insurance status, $\%^{\dagger}$} \\
\hline Private & 89.1 & 85.1 & 84.7 & 72.3 & 87.6 & $\begin{array}{c}87.1 \\
(83.3-90.9)\end{array}$ \\
\hline Medicaid & 10.9 & 14.9 & 15.3 & 27.7 & 12.4 & $\begin{array}{c}12.9 \\
(9.1-16.7)\end{array}$ \\
\hline Gravidity, mean n & 2.2 & 2.1 & 2.2 & 2.3 & 2.2 & $\begin{array}{c}2.2 \\
(2.1-2.3)\end{array}$ \\
\hline Parity, mean n & 0.76 & 0.68 & 0.77 & 0.83 & 0.71 & $\begin{array}{c}0.76 \\
(0.70-0.82)\end{array}$ \\
\hline Single, \%‡ & 12.5 & 13.9 & 16.1 & 21.9 & 15.9 & $\begin{array}{c}13.9 \\
(10.7-17.1)\end{array}$ \\
\hline Number of women & 552 & 308 & 399 & 424 & 371 & 2054 \\
\hline
\end{tabular}

Ob-Gyn - obstetrician-gynecologist, FP - family physician, CNM - certified nurse midwife, CI - confidence interval.

${ }^{*} P \leq .01$ across provider groups.

$\dagger P \leq .001$ across provider groups.

$\ddagger P \leq .05$ across provider groups.

$P$ values are presented for overall $F$ or chi-square tests (adjusted per SUDAAN).

sampled at the lowest rate and certified nurse midwives responded at the highest rate), and (2) interphysician differences in patient sampling rates (eg, 1 of 10 sampled patients abstracted from the qualifying panel of a physician with 100 low-risk patients would be weighted 10 times greater than would 1 of 10 patients from a physician who only had 10 low-risk patients).

We examined the use of MSAFP testing and the rate of patients' declining the MSAFP test for all women and then stratified the data by provider specialty and location and patient insurance status. Chi-square tests were used to examine whether there were statistically significant differences in our measures between the patients in the different groups. Logistic regression techniques were used to examine the use of MSAFP test ordering for patients of the different provider groups, controlling for a variety of patient and provider characteristics. The outcome variable of interest was whether the MSAFP test had been either ordered or performed versus not ordered or performed. Patient characteristics included age, race, parity, and Medicaid versus private insurance status. Provider characteristics included sex, practice set- ting (health maintenance organization [HMO], hospital, community clinic, and private practice), years in obstetric practice, solo versus group practice, and single versus multispecialty group. Similarly, logistic regression techniques were used within each specialty group to examine the use of MSAFP test ordering in the Medicaid and privately insured patient groups, controlling for other patient and provider characteristics.

While the patient weights produce unbiased statewide population estimates, the associated variances could be biased. For instance, because of the clustering of sampled patients to sampled providers, the patient-level data are not totally independent. A random-effects model (ie, SUDAAN program ${ }^{21}$ ) was applied to adjust the variance estimates appropriately. The resultant variance adjustments should result in confidence intervals and statistical significance tests that are both unbiased and conservative. Thus, the compensatory weights and variance adjustments should create representative statewide estimates. Even with these adjustments, the 95 percent confidence intervals of study estimates (as shown in the tables) are clearly narrow enough for meaningful analysis. 
Table 2. Provider Demographic, Training, and Practice Characteristics by Provider Group.

\begin{tabular}{|c|c|c|c|c|c|c|}
\hline Characteristics & $\begin{array}{l}\text { Urban } \\
\text { Ob-Gyn }\end{array}$ & $\begin{array}{c}\text { Rural } \\
\mathrm{Ob}-\mathrm{Gyn}\end{array}$ & Urban FP & Rural FP & $\begin{array}{l}\text { Urban } \\
\text { CNM }\end{array}$ & $\begin{array}{c}\text { Combined } \\
\text { Weighted } \\
\text { Estimates (CI) }\end{array}$ \\
\hline Age, mean $y^{\star}$ & 45.8 & 46.7 & 40.7 & 42.7 & 40.7 & $\begin{array}{c}42.8 \\
(41.7-43.9)\end{array}$ \\
\hline Female, $\%^{*}$ & 20.4 & 10.3 & 16.9 & 12.5 & 100.0 & $\begin{array}{c}21.9 \\
(16.5-27.3)\end{array}$ \\
\hline Residency trained, $\%^{\dagger}$ & 100.0 & 96.6 & 93.2 & 85.9 & NA & $\begin{array}{c}94.5 \\
(91.6-97.5)\end{array}$ \\
\hline Board certified, $\%^{\dagger}$ & 96.3 & 89.7 & 100.0 & 89.1 & 100.0 & $\begin{array}{c}96.9 \\
(94.9-98.9)\end{array}$ \\
\hline $\begin{array}{l}\text { Solo practice } \\
\text { (versus group), } \%^{\dagger}\end{array}$ & 27.8 & 31.0 & 25.4 & 10.9 & 11.6 & $\begin{array}{c}23.7 \\
(17.4-30.0)\end{array}$ \\
\hline \multicolumn{7}{|l|}{ Employer, \%* } \\
\hline Private & 92.6 & 96.6 & 69.5 & 93.8 & 23.3 & $\begin{array}{c}78.3 \\
(72.7-83.9)\end{array}$ \\
\hline $\begin{array}{l}\text { Health maintenance } \\
\text { organization }\end{array}$ & 3.7 & 0 & 15.3 & 0 & 34.9 & $\begin{array}{c}10.1 \\
(5.8-14.4)\end{array}$ \\
\hline University or hospital & 3.7 & 0 & 5.1 & 0 & 23.3 & $\begin{array}{c}4.8 \\
(1.8-7.8)\end{array}$ \\
\hline Community clinic & 0 & 3.4 & 10.2 & 6.3 & 18.6 & $\begin{array}{c}6.7 \\
(3.2-10.2)\end{array}$ \\
\hline $\begin{array}{l}\text { Obstetric patients initiating } \\
\text { care during study year, } \\
\text { mean } \mathbf{n}\end{array}$ & 114.0 & 101.4 & 25.2 & 28.9 & 42.6 & $\begin{array}{c}57.2 \\
(51.7-62.7)\end{array}$ \\
\hline Providers, $n$ & 54 & 29 & 59 & 64 & 43 & 249 \\
\hline
\end{tabular}

Ob-Gyn - obstetrician-gynecologist, FP - family physician, CNM - certified nurse midwife, CI - confidence interval.

" $P \leq 0.001$, across provider groups.

$\uparrow P \leq 0.05$, across provider groups.

$P$ values are presented for the overall $F$ or chi-square tests.

\section{Results}

This analysis included data on 2054 women who entered prenatal care in the first trimester and went through the course of the pregnancy with the same obstetric provider. The characteristics of the patients of the five provider groups are illustrated in Table 1. The overall mean age of women in the study was 26.4 years, with a range of 25.5 to 26.6 years. Most of the patients ( 90.0 percent) were non-Hispanic whites, married, and nulliparous. All of the patients had insurance, 87.1 percent private, 12.9 percent by the Medicaid program. The patients of rural family physicians were most likely to be insured by Medicaid and the patients of urban obstetrician-gynecologists least likely.

Characteristics of the providers (Table 2) revealed a narrow mean age range, 40.7 to 46.7 years. There were significant differences in age between the provider groups, with obstetrician-gynecologists older and certified nurse midwives and urban family physicians younger. Most physician pro-

viders were male (78.1 percent); all certified nurse midwives were female. Most providers were residency trained and board certified. Employer type was significantly different between provider groups, with obstetrician-gynecologists and rural family physicians most likely to be in private practice. Certified nurse midwives and urban family physicians were more often employed by HMOs, universities, hospitals, and community clinics than other providers. While the majority of all five provider types were in group practice, rural family physicians and certified nurse midwives were most likely to be in group practices. Obstetrician-gynecologists had the highest average number of patients initiating care during the study year, whereas family physicians had the lowest.

The use of MSAFP testing and the rate of patients' declining the test varied among the patients of the five provider groups (Table 3). Most patients (76.7 percent) had the test performed. The patients of urban and rural obstetrician-gynecologists were the most likely to have the test done $(80.4$ 
Table 3. MSAFP Test Ordering by Provider Group (weighted estimates).

\begin{tabular}{lcccc}
\hline Provider Group & Test Performed, \%* & $\begin{array}{c}\text { Test Offered but } \\
\text { Declined, \%* }\end{array}$ & $\begin{array}{c}\text { No Evidence } \\
\text { Test Was Performed } \\
\text { or Offered, \% }\end{array}$ & Number of Women \\
\hline Urban Ob-Gyn & 80.4 & 9.0 & 10.6 & 552 \\
Rural Ob-Gyn & 77.0 & 7.9 & 15.1 & 308 \\
Urban FP & 70.3 & 9.7 & 20.0 & 399 \\
Rural FP & 62.2 & 16.6 & 21.2 & 424 \\
Urban CNM & 64.2 & 26.1 & 9.7 & 371 \\
Combined weighted & 76.7 & 10.2 & 13.2 & 2054 \\
\multicolumn{1}{c}{ estimates (CI) } & $(71.3-82.1)$ & $(7.7-12.6)$ & $(8.1-18.3)$ & \\
\hline
\end{tabular}

Ob-Gyn - obstetrician-gynecologist, FP - family physician, CNM - certified nurse midwife, CI - confidence interval.

${ }^{\star} P \leq 0.001$, across provider groups.

$\dagger P \leq 0.01$, across provider groups.

$P$ values are presented for the overall chi-square tests across provider groups (by column) (adjusted per SUDAAN).

percent and 77.0 percent, respectively), whereas the patients of urban certified nurse midwives (64.2 percent) and rural family physicians (62.2 percent) were least likely to have the test done. A greater proportion of the patients of urban and rural family physicians had no record that the MSAFP test was either offered or performed (20.0 percent and 21.2 percent, respectively). The patients of certified nurse midwives (26.1 percent) were significantly more likely to decline MSAFP testing when offered (all pairwise $P$ values $<0.001$ ). No difference in these relations was found with logistic regression adjusting for patient and provider characteristics.

Women who were publicly insured by Medicaid were significantly less likely ( 60.5 percent) than privately insured women (79.1 percent) to have the MSAFP test performed (Table 4). Insurance type was not associated with patient response to the test - 11.3 percent of women insured by Medicaid and 10.0 percent of women with private insurance declined the test when it was offered. This difference between Medicaid and privately insured women was largely due to differences in MSAFPordering behavior by urban obstetrician-gynecologists and urban certified nurse midwives. The privately insured patients of urban obstetriciangynecologists were the most likely to have the test performed ( 83.8 percent), whereas the Medicaid patients of these providers were the least likely to have the test done ( 53.0 percent). The results were identical when repeated analyses included only those women with prenatal care visits between 15 and 20 weeks' gestation. Logistic regression controlling for patient and provider characteristics found that the Medicaid patients of urban obstetri- cian-gynecologists and certified nurse midwives were significantly less likely than their privately insured patients to have the MSAFP test offered or performed.

\section{Discussion}

This study has shown that providers and patients alike did not uniformly utilize the alpha-fetoprotein screening test for neural tube defects. There may be several reasons for this lack of uniformity. At the time this study was performed, there was ambiguity in the literature and from professional societies themselves regarding universal screening. 1,4,7,12-15,22 While the ACOG Department of Liability recommended that all patients be informed of the test in 1985,12 MSAFP screening was not recommended as a routine laboratory test until 1992 in ACOG guidelines. ${ }^{15}$ The American Society for Human Genetics issued a statement in 1987 that did not explicitly recommend universal screening, but listed requirements for an effective screening program. ${ }^{14}$ Although several experts were enthusiastic about the possibility of detecting a substantial number of affected pregnancies, they also expressed concerns about the complexity of the test and the high degree of coordination required for effective testing and follow-up. 1,7,13 Thus, while many obstetrician-gynecologists had been informed that lack of discussion of the MSAFP test could be a liability risk, it was not clear at the time of this study that offering the MSAFP test represented the standard of care.

The high false-positive rate with the MSAFP test might influence provider-ordering behavior. Although MSAFP screening detects 88 to 90 percent of affected pregnancies, neural tube defects 
Table 4. Use of MSAFP Test, Stratified by Provider Group and Insurance Status (weighted estimates).

\begin{tabular}{lcccc}
\hline $\begin{array}{l}\text { Provider } \\
\text { and Insurance }\end{array}$ & Test Performed, \% & $\begin{array}{c}\text { Test Offered but } \\
\text { Declined, \% }\end{array}$ & $\begin{array}{c}\text { No Evidence } \\
\text { Test Was Performed } \\
\text { or Offered, \% }\end{array}$ & Number of Women \\
\hline $\begin{array}{l}\text { Urban Ob-Gyn } \\
\quad \text { Medicaid }\end{array}$ & $53.0^{*}$ & & & \\
$\quad$ Private insurance & 83.8 & 9.8 & $37.2^{\star}$ & 65 \\
$\begin{array}{l}\text { Rural Ob-Gyn } \\
\quad \text { Medicaid }\end{array}$ & & 8.9 & 7.3 & 487 \\
$\quad$ Private insurance & 78.5 & 10.9 & 10.7 & 48 \\
Urban FP & 76.8 & 7.4 & 15.9 & 260 \\
$\quad$ Medicaid & & & & \\
$\quad$ Private insurance & 68.3 & 12.0 & 19.7 & 333 \\
Rural FP & 70.6 & 9.3 & 20.0 & 118 \\
$\quad$ Medicaid & & & & 306 \\
$\quad$ Private insurance & $70.6^{\dagger}$ & $11.5^{\dagger}$ & 17.9 & \\
Urban CNM & 59.0 & 18.6 & 22.4 & 66 \\
$\quad$ Medicaid & & & & 305 \\
$\quad$ Private insurance & 57.3 & 26.5 & 16.2 & \\
Combined weighted estimates: & 65.2 & 26.0 & 8.8 & 1691 \\
$\quad$ Medicaid & $60.5^{\dagger}$ & & & \\
$\quad$ Private insurance & 79.1 & 11.3 & 11.0 & \\
\hline
\end{tabular}

Ob-Gyn - obstetrician-gynecologist, FP - family physician, CNM - certified nurse midwife, CI - confidence interval.

$* P \leq 0.10$ between women with Medicaid and private insurance.

${ }^{\dagger} P \leq 0.05$ between women with Medicaid and private insurance.

$P$ values are presented for chi-square tests by provider type and test status (eg, for urban obstetrician-gynecologists comparison of difference for Medicaid and privately insured women in percentage who had MSAFP test performed, 53.0 versus 83.8).

are still a rare occurrence, 1 to $2 / 1000$ live births in the United States. Even a test with high sensitivity of 90 percent has a low positive predictive value in a population where the prevalence of disease is low. In the United Kingdom Collaborative Study where the prevalence of neural tube defects is higher, the positive predictive value of MSAFP screening was 31 percent. In the United States the positive predictive value is 2 to 4 percent. If 1000 patients are tested, 30 to 50 will have elevated levels on the first screening test, with only 1 or 2 actually having an open neural tube defect. ${ }^{5}$ To the provider of obstetric services, the opportunity costs are high: extensive pretest counseling, getting consent from all patients, and providing follow-up care for a substantial number of patients who will not have neural tube defects. This effort could either discourage providers from offering the test or affect the way in which providers offer the test, which in turn could strongly influence a patient's decision to have the test done. This might be the case for certified nurse midwives' patients, who are much more likely to decline the test when offered. Alternately, patients who choose certified nurse midwives might be less inclined to undergo MSAFP testing.

Patients' attitudes toward termination of pregnancy, even if complicated by a neural tube defect, could affect use of the MSAFP test. Providers' beliefs about termination might influence whether the test is offered and the way in which it is offered. A study of Minnesota family physicians who provide prenatal care found that providers were more likely to offer the test if they believed that abortions should be available either in general or to women with an affected fetus. ${ }^{19}$

The availability of amniocentesis and secondtrimester abortion might play a part in provider behavior. The patients of rural family physicians, who likely have less access to both of these procedures, were also least likely to have the MSAFP test offered or performed. Data from the 1990 Washington birth certificates indicate that among pregnant women older than 35 years of age, 19.4 percent living in rural areas compared with 30.5 percent living in urban areas had amniocentesis. These findings are consistent with other studies showing that rural women are less likely to use pre- 
natal genetic diagnostic testing. ${ }^{23,24}$ Madlon-Kay and colleagues ${ }^{19}$ also found that physicians offering MSAFP testing were more likely to work in large cities or suburbs.

Finally, some providers might not have been fully convinced of the cost effectiveness of universal MSAFP testing. Advocates of universal MSAFP screening relied on findings that the prenatal detection of neural tube defects would result in cost savings, assuming that all women with an affected pregnancy would choose elective termination. ${ }^{11}$ Providers might more readily see the emotional and financial costs of following up abnormal MSAFP test results, many of which will be falsely positive, and not see the less tangible long-term cost savings associated with aborting fetuses with neural tube defects. Madlon-Kay and colleagues ${ }^{19}$ found that only 27 percent of Minnesota family physicians responding to their survey believed that MSAFP testing was cost-effective. In addition, Taplin et $\mathrm{al}^{25}$ found that while there could be cost savings to society at large, insurers, especially in a managed care system, would experience losses if an MSAFP screening program were instituted. Whether this concern affected providers' decisions regarding MSAFP testing in this study is unknown.

That Medicaid patients were less likely to be offered MSAFP tests than privately insured patients is cause for concern. This finding suggests that some prenatal care providers were differentially offering this service to subgroups of their patients based on insurance status. The specialty analyses suggest that urban obstetrician-gynecologists and urban certified nurse midwives were largely responsible for this difference. In another analysis using these data, there were few differences in the number of prenatal and intrapartum resources used by Medicaid and privately insured women. ${ }^{26}$ Nonetheless, the current findings are consistent with a growing body of work showing that Medicaid patients or patients with demographic characteristics associated with Medicaid insurance status, such as being a racial or ethnic minority, are less likely to receive some medical advice, diagnostic tests, and therapeutic interventions than are their privately insured, white counterparts. ${ }^{27-31}$

This study is limited by several factors. First, our results are based on chart review. If the providers did not record that they offered the MSAFP test and the patient declined, then the pro- portion of patients that were not offered the test would be falsely elevated. Because charts, as well as the providers' notes, were reviewed for laboratory results, the rates of MSAFP test performance are less likely to be underestimated. In addition, the low number of abnormal MSAFP test results limits our ability to determine conclusively how abnormal MSAFP test results are followed up by various providers. Second, obstetrician-gynecologists had lower participation rates than family physicians or certified nurse midwives. If the obstetrician-gynecologists who were least likely to offer MSAFP testing were also less likely to participate in the study, the MSAFP test-ordering rates for obstetrician-gynecologists would be differentially elevated. Third, whereas our methods allowed us to report the overall MSAFP test-ordering rates for different provider groups, there could be a great deal of variation between individual providers within groups that our sampling strategy did not allow us to examine.

Despite these limitations, it is clear that there are differences in the rates of utilization of this test by patients and providers. Although it is not surprising that some patients chose not to have MSAFP testing, it is important that patients be informed of the availability of the test and educated about the implications of normal and abnormal test results. In 1988 the Washington State Legislature believed that it was so important that women be given information about MSAFP testing that it passed legislation requiring all obstetric providers to offer this test to their prenatal patients starting 1 January $1990 . .^{32}$ It is a concern that overall, 13 percent of Washington's pregnant women were not offered the MSAFP test and an even greater proportion of rural women were not offered the test.

Numerous advances have occurred since the data for this study were collected. There is now substantial evidence that high-level sonography, with emphasis on the central nervous system, can reduce the need for amniocentesis. ${ }^{33,34}$ Ultrasonic scanning is less costly, noninvasive, and provides results in less time than amniocentesis. The triple screen for MSAFP, human chorionic gonadotropin, and unconjugated estriol has replaced the MSAFP test alone in many settings and can detect those at greater and lesser risk for Down syndrome, creating a dual use for this test. ${ }^{16-18}$ Yet the counseling for and interpretation of the triple screen for Down syndrome risk is even more com- 
plex. The detection rate is lower and the false-positive rate higher using the triple screen for Down syndrome screening compared with the MSAFP test for neural tube defects. Patients have reported concerns with their screening experiences, and providers have reported problems in providing this test, including inadequate resources for counseling about a complex test and lack of confidence in counseling for Down syndrome screening. ${ }^{35-38}$ In addition, providers have been shown to have an incomplete understanding of the Down syndrome screening test. ${ }^{39}$ All these factors have the potential to produce more uncertainty and resultant variability in use of Down syndrome testing among providers and patients.

MSAFP screening and its related test, the triple screen, are complex, value laden, and require the timely coordination of prenatal and genetic services. Providers of obstetric services need educational programs that will assist them in understanding the capabilities and limitations of these tests, which can then be conveyed to their prenatal patients. Where MSAFP screening is mandated by law, efforts to ensure that necessary ancillary services are available in a timely fashion should be made.

Further studies are needed, both to examine the barriers to providers' offering the MSAFP or triple screen testing to their patients and to study whether the way in which providers offer the tests affects patient utilization. In addition, patterns of adoption of triple screen testing should be examined. Further work also is needed to explore the troubling finding that the Medicaid-insured patients of urban obstetrician-gynecologists are less likely than their privately insured patients to receive MSAFP testing.

\section{References}

1. Haddow JE, Macri JN. Commentary: prenatal screening for neural tube defects. JAMA 1979;242:515-6.

2. Chavez GF, Cordero JF, Becerra JE. Leading major congenital malformations among minority groups in the, United States 1981-1986. MMWR CDC Surveill Surmm 1988;37(3):17-24.

3. Althouse $R$, Wald N. Survival and handicap of infants with spina bifida. Arch Dis Child 1980;55:845-50.

4. Main DM, Mennuti MT. Neural tube defects: issues in prenatal diagnosis and counselling. Obstet Gynecol 1986;67:1-16.

5. American College of Obstetricians and Gynecologists. Alpha-fetoprotein. ACOG technical bulletin
154. Washington, DC: ACOG, 1991.

6. Ward NJ, Cuckle H, Brock JH, Peto R, Polani PE, Woodford FP. Maternal serum-alpha-fetoprotein measurement in antenatal screening for anencephaly and spina bifida in early pregnancy. Report of U.K. collaborative study on alpha-fetoprotein in relation to neural-tube defects. Lancet 1977;1:1323-32.

7. Macri JN, Haddow JE, Weiss RR. Screening for neural tube defects in the United States. A summary of the Scarborough Conference. Am J Obstet Gynecol 1979;133:119-25.

8. Milunsky A, Alpert E, Neff RK, Frigoletto FD Jr. Prenatal diagnosis of neural tube defects. IV. Maternal serum alpha-fetoprotein screening. Obstet Gynecol 1980;55:60-6.

9. Burton BK, Sowers SG, Nelson LH. Maternal serum alpha-fetoprotein screening in North Carolina: experience with more than twelve thousand pregnancies. Am J Obstet Gynecol 1983;146:439-44.

10. Cowan LS, Phelps-Sandall B, Hanson FW, Peterson AG, Tennant FR. A prenatal diagnostic center's first year experience with the California alpha-Fetoprotein Screening Program. Am J Obstet Gynecol 1989; 160:1496-504.

11. Layde PM, von Allmen SD, Oakley GP Jr. Maternal serum alpha-fetoprotein screening: a cost-benefit analysis. Am J Public Health 1979;69:566-73.

12. Annas GJ. Is a genetic screening test ready when the lawyers say it is? Hastings Cent Rep 1985;15:16-8.

13. Milunsky A, Haddow JE. Cautions about maternal serum alpha-fetoprotein screening. $\mathrm{N}$ Engl J Med 1985;313:694.

14. American Society of Human Genetics. Policy statement for maternal alpha-fetoprotein screening programs and quality control for laboratories performing maternal serum alpha-fetoprotein amniotic fluid and alpha-fetoprotein assays. Am J Hum Genet 1987; 40:75-82.

15. American Academy of Pediatrics: Committee on Fetus and Newborn; and American College of Obstetricians and Gynecologists: Committee on Obstetrics: Maternal and Fetal Medicine. Guidelines for perinatal care. 3rd ed. Elk Grove Village, Ill: American Academy of Pediatrics; Washington, DC: American College of Obsterricians and Gynecologists, 1992.

16. Haddow JE, Palomaki GE, Knight GJ, Williams J, Pulkkinen A, Canick JA, et al. Prenatal screening for Down's syndrome with use of maternal serum markers. N Engl J Med 1992;327:588-93.

17. Phillips OP, Elias S, Shulman LP, Andersen RN, Morgan CD, Simpson JL. Maternal serum screening for fetal Down syndrome in women less than 35 years of age using alpha-fetoprotein, hCG, and unconjugated estriol: a prospective 2-year study. Obstet Gynecol 1992;80(3 Pt 1):353-8.

18. Cheng EY, Luthy DA, Zebelman AM, Williams MA, Lieppman RE, Hickok DE. A prospective evaluation of a second-trimester screening test for fetal Down 
syndrome using maternal serum alpha-fetoprotein, hCG, and unconjugated estriol. Obstet Gynecol 1993;81:72-7.

19. Madlon-Kay DJ, Reif C, Mersy DJ, Luxenberg MG. Maternal serum alpha-fetoprotein testing: physician experience and attitudes and their influence on patient acceptance. J Fam Pract 1992;35:395-400.

20. Baldwin LM, Raine T, Jenkins LD, Hart LG, Rosenblatt RA. Do providers adhere to ACOG standards? The case of prenatal care. Obstet Gynecol 1994;84:549-56.

21. Shah BV, Folsom RE, LaVange LM, Whelless SC, Boyle KE, Williams RL. Statistical methods and mathematical algorithms used in SUDAAN. Research Triangle Park, NC: Research Triangle Institute, 1993.

22. Burton BK. Maternal serum alpha-fetoprotein screening. Pediatr Ann 1989;18:687-92, 694-7.

23. Sokal DC, Byrd JR, Chen AT, Goldberg MF, Oakley GP Jr. Prenatal chromosomal diagnosis: racial and geographic variation for older women in Georgia. JAMA 1980;244:1355-7.

24. Halliday J, Lumley J, Watson L. Comparison of women who do and do not have amniocentesis or chorionic villus sampling. Lancet 1995;345:704-9.

25. Taplin SH, Thompson RS, Conrad DA. Cost-justification analysis of prenatal maternal serum alpha-feto protein screening. Med Care 1988;26:1 185-202.

26. Dobie S, Hart LG, Fordyce M, Andrilla CHA, Rosenblatt RA. Obstetric care and payment source: do low-risk Medicaid women get less care? Am J Public Health, 1998;88:51-6.

27. Ayanian JZ, Udvarhelyi IS, Gatsonis CA, Pashos CL, Epstein AM. Racial differences in the use of revascularization procedures after coronary angiography. JAMA 1993;269:2642-6.

28. Greenberg ER, Chute CG, Stukel T, Baron JA, Freeman DH, Yates J, et al. Social and economic factors in the choice of lung cancer treatment. A population-based study in two rural states. N Engl J Med
1988;318:612-7.

29. Wenneker MB, Weissman JS, Epstein AM. The association of payer with utilization of cardiac procedures in Massachusetts. JAMA 1990;264:1255-60.

30. Braveman PA, Egerter S, Bennett T, Showstack J. Differences in hospital resource allocation among sick newborns according to insurance coverage. JAMA 1991;266:3300-8.

31. Kogan MD, Kotelchuck M, Alexander GR, Johnson WE. Racial disparities in reported prenatal care advice from health care providers. Am J Public Health 1994;84:82-8.

32. Wash Rev Code $\$ 70.54 .220$ (1988).

33. Nadel AS, Green JK, Holmes LB, Frigoletto FD Jr, Benacerraf $B R$. Absence of need for amniocentesis in patients with elevated levels of MSAFP and normal ultrasonographic examinations. $\mathrm{N}$ Engl J Med 1990;323:557-61.

34. Richards DS, Seeds JW, Katz VL, Lingley LH, AJbright SG, Cefalo RC. Elevated maternal serum alpha-fetoprotein with normal ultrasound: is amniocentesis always appropriate? A review of 26,069 screened patients. Obstet Gynecol 1988;71:203-7.

35. Statham H, Green J. Serum screening for Down's syndrome: some women's experiences. BMJ 1993; 307:174-6.

36. Salonen R, Kurki L, Lappalainen M. Experiences of mothers participating in maternal serum screening for Down's syndrome. Eur J Hum Genet 1996;4: 113-9.

37. Khalid L, Price SM, Barrow M. The attitudes of midwives to maternal serum screening for Down's syndrome. Public Health 1994;108:131-6.

38. Green JM. Serum screening for Down's syndrome: experiences of obstetricians in England and Wales. BMJ 1994;309:769-72.

39. Sadler M. Serum screening for Down's syndrome: how much do health professionals know? Br J Obstet Gynaecol 1997;104:176-9. 